\title{
Analyzing the Process from the Initiation of Attack to Goal Scoring Touch in the EURO 2016
}

\author{
Erdi Tokul ${ }^{1, *}$, Olcay Mülazımoğlu ${ }^{2}$ \\ ${ }^{1}$ Trabzonspor A. Ş. First Team Match and Performance Analyst, Trabzon, Turkey \\ ${ }^{2}$ Faculty of Sports Sciences, Muğla Sıtkı Koçman University, Muğla, Turkey
}

Copyright $\odot 2018$ by authors, all rights reserved. Authors agree that this article remains permanently open access under the terms of the Creative Commons Attribution License 4.0 International License

\begin{abstract}
The purpose of this study is to carry out a technical and tactical analysis of the process from the initiation of attack to goal scoring touch in the EURO 2016. The study analyzed a total of 108 goals scored. Chi-square analysis was used to determine the statistically significant differences and the level of significance was set at $\mathrm{p}<0.05$. The analysis excluded 11 goals scored including 3 own goals and 8 penalty goals; thus, 97 goals were analyzed. The analysis results showed that most goals (59.26\%) were scored in the second half of matches, after attacks originating from the defending third $(41.2 \%)$, with the contribution of 4 players $(29.63 \%)$, inside the penalty area $(72.22 \%)$, with instep shots $(20.5 \%)$, and with one touch (60.8\%). The study found that at the top-level EURO 2016, scorings were more effective in the second half, after attacks originating from the defending third, with different numbers of passes, from the centre or wings, with passes to the penalty area, one touch and instep shots. To achieve technical and tactical efficiency in football, guidance for coaches in light of this information can make a significant contribution to coach and players.
\end{abstract}

Keywords EURO 2016 Analyzing, Scoring Touch, Soccer Analysis

\section{Introduction}

Soccer has now become a game that is played faster and in smaller areas; thereby necessitating research to improve player and team performance through technical and tactical analyses of matches. Such research should be based on concrete, well-visualized statistical data. Match analysis enables an objective reporting of player and team behaviours during the competition according to certain criteria (1). The main purpose of a match analysis is to identify the strengths, weaknesses and potentialities of your team and to offer recommendations for improvements. A coach also wants to know and make use of all such features about the opposing team (2).

In the matches, a goal is the extreme point of the game and is the ultimate target. Teams are set up in tactical training for the most effective attack and a better defence against the opponent to change the game score and ultimately to achieve this goal. There is a great volume of research analyzing the characteristics of goals scored in top-level football tournaments; however, re-evaluations are needed since football characteristics change constantly. Additionally, the data collected through such research and provided to coaches and players are of great importance for the design of training, the selection of appropriate tactics, and the in-game use of tactics $(3,4,5,6)$.

This study aimed to analyze goals scored at the EURO 2016 according to a set of criteria including the period of goals scored, the initiation zone of the attack prior to goal scoring, the field of the game where the attack is continued, the number of passes of the scoring team, number of players contributing to goal scoring, scoring position, shooting type, and the number of touches.

\section{Method}

\subsection{Sample}

The study analyzed 108 goals scored in 51 matches played between 24 teams at the 2016 European Football Championship held in France (EURO 2016 France). The study was carried out in line with the approval of the Health Sciences Ethics Committee, Muğla Sitkı Koçman University.

\subsection{Procedures}

The data were collected using official overviews of plays from the database on the website of the Union of European Football Associations (UEFA) (7). A document analysis was performed as the method of data collection within the context of a descriptive approach (8). The video recordings of goals scored in the competitions were classified 
according to the criteria established by the competition the football analysis program (e-analyze pro-soccer). The following variables were as the criteria for analysis:

a) Period of goals scored (first half and second half)

b) Initiation zone of the attack prior to goal scoring (first third/defending third, middle third, and final third/attacking third,)

c) Attacking area (field of game where the attack is continued), (left wing, centre, and right wing)

d) Number of passes of the scoring team (after a sequence of 1-3 passes, 4-6 passes, and 7 and more passes)

e) Number of players contributing to goal scoring (individual action, 1, 2, 3, 4, and 5 and more players)

f) Scoring position (inside the penalty area, outside the penalty area)

g) Shooting type (inside of the foot, instep shot, header and touch-in)

h) Number of touches (one touch, two touches, and three and more touches)

\subsection{Data Analysis}

The frequency and percentage distribution of goals were analyzed according to the set of criteria. The Chi-square test was used to analyze differences between distributions. The analysis results were presented in tables. For the chi-square test, $\mathrm{p}<0.05$ and $\mathrm{p}<0.01$ were considered as the level of significance.

\section{Findings}

The EURO 2016 was contested by the 24 qualified teams drawn into six groups of four teams. Each group had six matches and the group stage had 36 matches. 16 teams consisting of the top two from each group and the four best third-ranked teams went through to the knockout phase. 8 teams advanced to the quarter-finals in the 8 matches of the round-of-16 knockout stage. Four knockout matches were played in the quarterfinals and 4 teams reached the semi-finals. After the two knockout matches between the 4 semi-finalists, France and Portugal, the winners of the semi-finals, played the final competition. Portugal won UEFA EURO 2016 with the goal scored in the second half of extra time. A total of 51 matches played and 108 goals were scored at the Euro 2016.

108 goals scored at the Euro 2016, 42 (38.89\%) were scored in the first half of matches, $64(59.26 \%)$ in the second half, 2 goals $(1.85 \%)$ in extra time. A significant difference was found between the distribution of goals scored in halves $\left(X^{2}=4.57 ; p<0.05\right)$. The number of goals scored in the second half of matches was higher than those in the first half (Table 1).

Table 1. Distribution of goals per period

\begin{tabular}{|c|c|c|c|c|c|c|}
\hline \multicolumn{2}{|c|}{ Criteria } & Number of Goals (f) & Percentage of Goals (\%) & Chi-square $\left(X^{2}\right)$ & df & $\mathbf{p}$ \\
\hline \multirow{3}{*}{ Period } & $1^{\text {st }}$ Half & 42 & 38.89 & \multirow{2}{*}{$4.57 *$} & \multirow{2}{*}{1} & \multirow{2}{*}{0.033} \\
\hline & $2^{\text {nd }}$ Half & 64 & 59.26 & & & \\
\hline & Extra Time ${ }^{a}$ & 2 & 1.85 & - & - & - \\
\hline
\end{tabular}

Table 2. Distribution of scoring according to the initiation zone, attacking area and the Scoring position

\begin{tabular}{|c|c|c|c|c|c|c|}
\hline Criteria & & Number of Goal (f) & Percentage of Goals (\%) & Chi-square $\left(X^{2}\right)$ & df & $\mathbf{p}$ \\
\hline \multirow{4}{*}{ Initiation Zone } & First third & 40 & 37.04 & \multirow{3}{*}{$28.67 * *$} & \multirow{3}{*}{2} & \multirow{3}{*}{0.000} \\
\hline & Middle third & 17 & 15.74 & & & \\
\hline & Final third & 6 & 5.56 & & & \\
\hline & Other $^{b}$ & 45 & 41.67 & - & - & - \\
\hline \multirow{4}{*}{ Attacking Area } & Centre & 23 & 21.30 & \multirow{4}{*}{3.93} & \multirow{4}{*}{3} & \multirow{4}{*}{0.270} \\
\hline & Left wing & 28 & 25.93 & & & \\
\hline & Right wing & 22 & 20.37 & & & \\
\hline & Other & 35 & 32.41 & & & \\
\hline \multirow{3}{*}{ Scoring Position } & $\begin{array}{l}\text { Inside the } \\
\text { penalty area }\end{array}$ & 78 & 72.22 & \multirow{2}{*}{$35.89 * *$} & \multirow{2}{*}{1} & \multirow{2}{*}{0.000} \\
\hline & $\begin{array}{l}\text { Outside the } \\
\text { penalty area }\end{array}$ & 19 & 17.59 & & & \\
\hline & Other $^{c}$ & 11 & 10.19 & - & - & - \\
\hline \multicolumn{7}{|c|}{$\begin{array}{l}{ }^{*} \mathrm{p}<0.05 * * \mathrm{p}<0.01 \text { level of significance. } \\
\mathrm{b}<\text { Other referring to set-play goals, own goals and penalty goals was excluded from the chi-square analysis } \\
\mathrm{c} \text { Other referring to own goals and penalty goals was excluded from the chi-square analysis. }\end{array}$} \\
\hline
\end{tabular}


40 goals $(37.04 \%)$ were scored after attacks originating from the first third, 17 goals $(15.74 \%)$ were scored attacks from the middle third, and 6 goals $(5.56 \%)$ were scored attacks from the final third. A significant difference was found between the distributions according to the initiation zone $\left(\mathrm{X}^{2}=28.67 ; \mathrm{p}<0.01\right)$. Most goals were scored from attacks originating from the first third (Table 2).21.30\% goals began from the central zone, $25.93 \%$ from the left wing, and $20.37 \%$ from the right zone. No difference was found between the distributions of goals scored according to the field of game $\left(\mathrm{X}^{2}=3.93 ; \mathrm{p}>0.05\right)$ (Table 2$)$.

Considering the scoring position, most goals (78 goals, $72.22 \%$ ) were scored inside the penalty area, while 19 goals $(17.59 \%)$ were scored outside the penalty area. A significant difference was found between the distributions $\left(\mathrm{X}^{2}=35.89 ; \mathrm{p}<0.01\right)$ (Table2).

No significant difference was found between the distributions of goals scored after a sequence of 1-3 passes,
4-6 passes, and 7 and more passes in terms of the effect of the number of passes ( $\mathrm{p}>0.05)$ (Table 3$)$.

Considering the number of players contributing to goal scoring, the number of goals contributed by 4 players (32 goals, $29.63 \%$ ) were significantly higher compared to other instances $\left(\mathrm{X}^{2}=28.66 ; \mathrm{p}<0.01\right)$ (Table 3$)$.

Instep shots accounted for the highest percentage with 54 goals scored $(50 \%)$, followed by inside the foot with 25 goals scored $(23.15 \%)$, header with 22 goals scored $(20.37 \%)$, and touch-ins/deflections with 4 goals scored $(3.70 \%)$. There was a significant difference between the distributions $\left(X^{2}=48.94 ; \mathrm{p}<0.01\right)$ (Table 4).

Considering the number of touches by the scorer, one touch accounted for the highest percentage with 59 goals scored $(54.63 \%)$, followed by 2 touches with 19 goals scored $(17.59 \%)$, and 3 and more touches with 15 goals scored $(13.89 \%)$. A significant difference was found between the distributions $\left(\mathrm{X}^{2}=38.19 ; \mathrm{p}<0.01\right)$ (Table 4).

Table 3. Distribution of goals according to the number of passes prior to goal scoring and the number of players contributing to goal scoring

\begin{tabular}{|c|c|c|c|c|c|c|}
\hline \multicolumn{2}{|c|}{ Criteria } & \multirow{2}{*}{$\begin{array}{c}\text { Number of Goals (f) } \\
34\end{array}$} & \multirow{2}{*}{$\begin{array}{c}\begin{array}{c}\text { Percentage of Goals } \\
(\mathbf{\%})\end{array} \\
31.48\end{array}$} & $\begin{array}{c}\text { Chi-square } \\
\text { (X2) }\end{array}$ & df & $\mathbf{p}$ \\
\hline \multirow{4}{*}{ Number of passes } & 1-3 passes & & & \multirow{3}{*}{3.37} & \multirow{3}{*}{2} & \multirow{3}{*}{0.186} \\
\hline & 4-6 passes & 23 & 21.30 & & & \\
\hline & $\begin{array}{l}7 \text { and more } \\
\text { passes }\end{array}$ & 22 & 20.37 & & & \\
\hline & Other $^{d}$ & 29 & 26.85 & - & - & - \\
\hline \multirow{6}{*}{ Number of players } & Individual & 16 & 14.81 & \multirow{6}{*}{$28.66^{* *}$} & \multirow{6}{*}{5} & \multirow{6}{*}{0.000} \\
\hline & 1 Player & 11 & 10.19 & & & \\
\hline & 2 Players & 23 & 21.30 & & & \\
\hline & 3 Players & 20 & 18.52 & & & \\
\hline & 4 Players & 32 & 29.63 & & & \\
\hline & 5+ Players & 3 & 2.78 & & & \\
\hline
\end{tabular}

Table 4. Distribution of goals according to the shooting type of scorer and the number of ball touches

\begin{tabular}{|c|c|c|c|c|c|c|}
\hline \multicolumn{2}{|c|}{ Criteria } & Number of Goals (f) & Percentage of Goals (\%) & Chi-square $\left(X^{2}\right)$ & df & $\mathbf{p}$ \\
\hline \multirow{4}{*}{ Shooting type } & Inside of the foot & 25 & 23.15 & \multirow{4}{*}{$48.94 * *$} & \multirow{4}{*}{3} & \multirow{4}{*}{0.000} \\
\hline & Instep shot & 54 & 50.00 & & & \\
\hline & Header & 22 & 20.37 & & & \\
\hline & Touch-in & 4 & 3.70 & & & \\
\hline \multirow{4}{*}{$\begin{array}{l}\text { Number of } \\
\text { ball touches }\end{array}$} & One touch & 59 & 54.63 & \multirow{3}{*}{$38.19 * *$} & \multirow{3}{*}{2} & \multirow{3}{*}{0.000} \\
\hline & 2 touches & 19 & 17.59 & & & \\
\hline & $\begin{array}{l}3 \text { and more } \\
\text { touches }\end{array}$ & 15 & 13.89 & & & \\
\hline & Other $^{\mathrm{e}}$ & 15 & 13.89 & - & - & - \\
\hline
\end{tabular}




\section{Discussion and Conclusions}

The result that $59.26 \%$ of goals were scored in the second half of matches at the UEFA Euro 2016 is consistent with previous research. The ratio of goals scored in the second half at FIFA World Cup, UEFA European Championship, and national league tournaments has been reported to be higher than that of goals in the first half $(3,9,5,6,10,11)$.

At the Euro 2004, 42.6\% of goals were scored in the first half of matches, while $57.4 \%$ were scored in the second half (3). At the Euro 2012, 42.1\% of goals were scored in the first half and $57.9 \%$ were in the second half (9).

Among a total of 10,885 goals scored in 4,560 matches in English, French Ligue 1, Italian and Spanish leagues, $44.9 \%$ were scored in the first half and $55.1 \%$ were in the second half (5). At the 2006 FIFA World Cup, $47.5 \%$ of goals were scored in the first half of matches and $52.5 \%$ were in the in the second half (6). Some national leagues and championships also had $43.8 \%$ of goals in the first half and 56.2 in the second half (10). At the 1995, 1999, and 2003 Women's World Cups, the ratio of first-half goals was $46.5 \%, 42.3 \%$, and $42 \%$ and that of second-half goals was $53.5 \%, 57.7 \%$, and $58 \%$, thereby leading to significant differences (11).

Some research results, not running in similar with the present study, showed that the initiation zone of the attack prior to goal scoring was mostly the final third $(12,13)$. Hughes and Snook (14) also reported the effectiveness and advantage of attacking possessions originated in the final third. At the 2012 European Football Championship, more goals were scored after attacks originating from the central zone (12), which is not consistent with the result of the present study. Apparently, goals scored in the UEFA 2012 and 2016 tournaments differ in the use of the field of game. It seems that the use of the field of game in goal attempts was versatile at the Euro 2016.

Previous research stressed that teams scored more goals after a sequence of $4-5$ passes $(12,15)$. The results of the present study, however, showed that more goals (31.48\%) were scored after 1-3 passes. Thus, it seems that, in terms of the number of passes, there was a change in goals scored at the Euro 2016 compared to previous championships; goals were mostly scored after fewer passes.

The results of this study run similar with previous research reporting that scorers shoot at goal with the least number of touches after an assist. The technical importance of one-touch goals is highlighted in top-level football competitions. Additionally, the analysis of top-level tournaments reports that goals are mostly scored inside the penalty area and with foot kicks $(6,12,16,17)$.

In conclusion, the study found that at the top-level European Football Championships, shots at goals were more effective in the second half, after attacks originating from the defending third, with different numbers of passes, from the centre or wings, with passes to scorer inside the penalty area, and with one touch and instep shots. To achieve technical and tactical efficiency in football, guidance for trainers in light of this information can make a significant contribution to coach and football players.

\section{REFERENCES}

[1] Carling, C., Williams, A., \& Reilly, T. (2005). The handbook of soccer match analysis. London: Routledge.

[2] Carling, C., Le Gall, F., Reilly, T., \& Williams, A. M. (2009). Do anthropometric and fitness characteristics vary according to birth date distribution in elite youth academy soccer players?. Scandinavian journal of medicine \& science in sports, 19(1), 3-9.

[3] Yiannakos, A., Armatas, V. (2006). Evaluation of the goal scoring patterns in European Championship in Portugal 2004. International Journal of Performance Analysis in Sport, 6 (1), pp. 178-188.

[4] Armatas, V., Yiannakos, A., Papadopoulou, S., Skoufas, D. (2009). Evaluation of goals scored in top ranking soccer matches: Greek "Super League" 2006-07. Serbian Journal of Sports Sciences, 3 (1), pp. 39-43.

[5] Alberti, G., Iaia, F. M., Arcelli, E., Cavaggioni, L., \& Rampinini, E. (2013). Goal scoring patterns in major European soccer leagues. Sport Sciences for Health, 9(3), 151-153.

[6] Armatas, V., \& Yiannakos, A. (2010). Analysis and evaluation of goals scored in 2006 World Cup. Journal of Sport \& Health Research, 2, 119-128.

[7] UEFA (2017). Retrieved on 21.06.2017 from http://www.uefa.com/uefaeuro/history/ index.html.

[8] Özkara, AB. (2018) Physical education in EU schools and Turkey: A comparative study. Comparative Professional Pedagogy 8(2), 101-106.

[9] Leite, S.S.W. (2013a). Euro 2012: analysis and evaluation of goals scored. International Journal of Sports Science, 3(4), 102-106.

[10] Njororai, W.S.S. 2014. Timing of Goals Scored in Selected European and South American Soccer Leagues, FIFA and UEFA Tournaments and the Critical Phases of a Match. International Journal of Sports Science, s. 56-64.

[11] Armatas, V., Yiannakos, A., Galazoulas, C., \& Hatzimanouil, D. (2007). Goal scoring patterns over the course of a match: Analysis of Women's high standard soccer matches. Physical Training, 1(1).

[12] Mitrotasios, M., \& Armatas, V. (2014). Analysis of Goal Scoring Patterns in the 2012 European Football Championship. Retrieved February 18, 2014, from $\mathrm{http}$ ://thesportjournal.org/article/analysis-of-goal-scoring-p atterns-in-the-2012-european-football-championship.

[13] Tenga, A., Holme, I., Ronglan, L. T., \& Bahr, R. (2010). Effect of playing tactics on achieving score-box possessions in a random series of team possessions from Norwegian professional soccer matches. Journal of sports sciences, 
$28(3), 245-255$.

[14] Hughes, M., \& Snook, N. (2006). Effectiveness of attacking play in the 2004 European Championships. In H. Dancs, M. Hughes, \& P. G. O'Donoghue (Eds.), Proceedings of the World Congress of Performance Analysis of Sport 7 ( $\mathrm{pp}$. 46-62). Cardiff: CPA UWIC Press.

[15] Çakıroğlu, M. (2005). Türkiye Süper Ligi futbol maçların uygulanan hücum organizasyonlarının karşılaştırmalı analizi ve maç sonuçlarına etkisinin incelenmesi. Doktora Tezi, Marmara Üniversitesi Sağlık Bilimleri Enstitüsü Beden Eğitimi ve Spor Anabilim Dalı, İstanbul.

[16] Michaildis Y, Michaildis C, Primpa E, (2013). Analysis of goals scored in European Championship 2012. J Hum Sport Exer.8(2): 367-375.

[17] Durlik, K., \& Bieniek, P. (2014). Analysis of goals and assists diversity in English Premier League. Journal of Health Sciences, 4(05), 047-056.

i This study is derived from the master's thesis entitled "Investigation of Goals scored and Shots in 2016 European Football Championship in terms of Tactical and Technical Criteria" authored by Erdi Tokul (2017) and accepted by the Department of Physical Education and Sports, Graduate School of Medical Sciences, Muğla Sitkı Koçman University.

* This study was presented as a poster at the $15^{\text {th }}$ International Sports Science Congress held on November 15-18, 2017 in Antalya. 